\title{
Bcl-2 proapoptotic proteins distribution in U-87 MG glioma cells before and after hypericin photodynamic action *
}

\author{
Lucia Balogová, Mária Maslaňáková, Lenka Dzurová, Pavol Miškovský and Katarína \\ Štroffeková
}

Department of Biophysics, Institute of Physics, P. J. Safarik University, Kosice, Slovak Republic

\begin{abstract}
Apoptosis is a key process in the development and maintenance of tissue homeostasis. This process of controlled cell death is tightly regulated by a balance between cell survival and damage signals. We focused our attention towards one apoptotic pathway, the intrinsic mitochondrial one where Bcl-2 family of proteins plays the major role. We are particularly interested in two pro-apoptotic players Bak and Bax from this family. Here we investigated their role in apoptosis triggered by photodynamic action. Targeted photodynamic therapy (PDT) is a promising approach to diagnose and treat different types of cancer. We show the localization of Bax and Bak in U-87 MG human glioma cells incubated with photosensitizer hypericin (Hyp) before and after photodynamic action. Apoptotic stimulus by Hyp photodynamic action causes Bax translocation into mitochondria. However, our results suggest that under these conditions there are two populations of mitochondria: one which contains Bax and Bak simultaneously, and is almost exclusively localized near the plasma membrane; the other which contains Bax only and is distributed throughout the cell. The different protein content and spatial distribution of these two populations suggest that they can play different roles in response to apoptotic stimuli.
\end{abstract}

Key words: Apoptosis - Bcl-2 proteins - Hypericin - PDT - Mitochondria

\begin{abstract}
Abbreviations: Ab, antibody; Bak, Bcl-2 homologous antagonist/killer; Bax,Bcl-2-associated X protein; Bcl-2, B-cell lymphoma 2; Bcl- $x_{\mathrm{L}}$, B-cell lymphoma-extra large; Hyp, Hypericin; $\mathrm{MetOH}$, methanol; OMM, outer mitochondrial membrane; PDT, photodynamic therapy; ROS, reactive oxygen species.
\end{abstract}

\section{Introduction}

In multi-cellular organisms, apoptosis is a key process in the development and maintenance of tissue homeostasis. This process of controlled cell death is tightly regulated by a balance between cell survival and damage signals. The absence of cell survival signals triggers apoptosis, a morphologically distinct form of cell death (Renno et al. 2000; Hsiao et al.

Correspondence to: Katarína Štroffeková, Department of Biophysics, Institute of Physics, P. J. Safarik University, Jesenná 5, 04154 Košice, Slovak Republic

E-mail: katarina.stroffekova@upjs.sk

* This article was presented at the $5^{\text {th }}$ Slovak Biophysical Symposium, organized by The Slovak Biophysical Society in Bratislava, March 19-21, 2012
2009). Dysregulation of apoptosis can contribute to diverse pathologic processes. For instance, diminished apoptosis is crucial for tumor growth (Chavakis and Dimmeler 2002), while excessive apoptosis is associated with infection, atherosclerosis, inflammatory and autoimmune diseases (Hsiao et al. 2009). Therefore, understanding apoptosis regulatory mechanisms has great importance for the development of novel therapy strategies for cancer and other pathologies.

Apoptosis can be initiated by extrinsic factors, such as ligands for cell surface death receptors, or intrinsically by responding to damage and stress. It is known that several apoptotic pathways coexist in mammalian cells that are preferentially activated in a stimulus-, stage-, context-specific and cell-type manner (Hakem et al. 1998). A common mechanism causing cell damage and apoptosis is oxidative stress with the generation of radical oxygen species (ROS). 
The mechanisms by which ROS may cause or regulate apoptosis typically include death receptor activation, caspase activation, Bcl-2 family proteins, and mitochondrial dysfunction (Hsiao et al. 2009). In most cases, cells undergo oxidative stress related apoptosis via an intrinsic death pathway, in which mitochondria and Bcl-2 family of proteins play a key role (Hsiao et al. 2009; Kroemer 1997). Bcl-2 proteins can act as either pro-apoptotic or anti-apoptotic regulators (Kroemer 1997; Youle and Strasser 2008), and their primary site of action is on the outer mitochondrial membrane (OMM). Interplay between $\mathrm{Bcl}-2$ proteins regulates permeabilization of OMM and the release of apoptogenic factors from the intermembrane space into the cytoplasm, which is a critical point of no return in apoptosis (Lindsay et al. 2011). However, mitochondria is not the only site of $\mathrm{Bcl}-2$ proteins action, there are reports of $\mathrm{Bcl}-2$ proteins localization and function on the endoplasmic reticulum and in the nucleus (Scorrano et al. 2003; Annis et al. 2004; Buytaert et al. 2006; Hwang et al. 2006). The mechanisms for how survival or death signals lead to the activation of the $\mathrm{Bcl}-2$ proteins and their targeting specifically on the mitochondria are still not well understood (Lindsay et al. 2011). In normal healthy cells, most anti-apoptotic multi-domain Bcl-2 family members are constitutively found in the OMM or the endoplasmic reticulum. The multi-domain pro-apoptotic protein Bak is constitutively localized to the OMM. Conversely, Bax is predominantly found in the cytosol and is recruited to the OMM upon receipt of an apoptotic signal (Gopinget al. 1998; Gilmore et al.2000). However, Bax is not exclusively cytosolic prior to apoptosis, and detectable amounts can be seen on mitochondria in healthy cells (Nechushtan et al. 1999). Furthermore, Bax translocation to mitochondria alone does not commit a cell to undergo apoptosis (Nechushtan et al. 1999; Valentijn et al. 2003).

The generation of ROS in cells can be triggered by endogenous stimuli such as aging, hypoxia, inflammation (Steinberg et al. 2007), and by artificial stimuli such as chemo- and photodynamic therapy (Reeves et al. 2009). Photodynamic therapy (PDT) is a treatment for benign, premalignant and malignant conditions currently used in clinical practise. PDT is based on the concept that the combination of a photosensitizing agent with light and molecular oxygen leads to the formation of singlet oxygen and free radicals (ROS) causing selective damage to the target tissue (Steinberg et al. 2007). Tumor response to PDT is variable, ranging from high sensitivity to extreme resistance (Reeves et al. 2009).

Here, we focused our attention on studying cell responses to Hypericin (Hyp) photodynamic action in human glioma derived cell line U-87 MG. Hyp, a naturally occurring photosensitizer, displays antiproliferative and cytotoxic effects in many tumor cell lines including U-87 MG line (Agostinis 2002; Kiesslich et al. 2006; Kascakova et al. 2008; Kleban et al. 2008). Hyp's interesting photosensitizing properties together with its selective uptake in tumor tissues, and its minimal dark cytotoxicity, make it promising for the clinical use in the PDT (Agostinis et al. 2002; Miskovsky 2002; Kiesslich et al. 2006). The pronounced hydrophobic character predisposes Hyp to cross plasma membrane and localize in cell membranous organelles. The Hyp accumulation has been studied with different fluorescent organelle markers in various cancer cell lines, and the main centers of accumulation were the endoplasmic reticulum and Golgi complex (English et al. 1999; Ali and Olivo 2002), lysosomes (Siboni et al. 2002; Buytaert et al. 2006; Theodossiou et al. 2006; Kascakova et al. 2008), and mitochondria (Theodossiou et al. 2006; Gallanou et al. 2008). In addition, it has been proposed that the mitochondria (Theodossiou et al. 2006) and SERCA2 protein in the endoplasmic reticulum (Buytaert et al. 2006) are the primary targets of Hyp phototoxicity. Moreover, it has been shown that without the presence of Bax and Bak proteins, cells treated with Hyp photodynamic action cannot undergo apoptosis (Buytaert et al. 2006), suggesting that mitochondria and Bax/Bak regulated mechanism are the key players in HypPDT triggered apoptosis.

Human malignant glioma cells including U-87 MG express proteins of $\mathrm{Bcl}-2$ family including $\mathrm{Bcl}-2, \mathrm{Bcl}-\mathrm{XL}$, Bax and Bak (Rieger et al. 1998; Cerrato et al. 2001; Wang et al. 2011). Cells display the specific temporal and spatial patterns of Bcl-2 member expression in a stimulus- and context-specific manner (Renno et al. 2000; Bhuvaneswari et al. 2007). In the present study, we focused on distribution of two pro-apoptotic proteins Bax and Bak in the U-87 MG cells because of following. The temporal and spatial expression patterns of Bax and Bak in the U-87 MG cells before and after HypPDT have not been addressed in detail, and because of reported localization of Bax and Bak on the endoplasmic reticulum and in the nucleus (Scorrano et al. 2003; Annis et al. 2004; Buytaert et al. 2006; Hwang et al. 2006), besides their usually assigned cytosol and mitochondria, respectively.

We studied expression patterns of Bax and Bak by immunocytochemistry in U-87 MG glioma cells before and after HypPDT, and discovered an occurrence of two distinct mitochondria populations. One contained both proteins simultaneously and the other contained Bax only. Under control conditions, Bax was localized in cytosol and in small portion was peripherally attached to mitochondria. Bak was localized predominantly in mitochondria which were distributed homogenously throughout the cell. After an apoptotic stimulus (HypPDT), Bak containing mitochondria were located predominantly at the plasma membrane, and Bax translocated from cytosol to mitochondria. Mitochondria containing Bax and Bak simultaneously were almost exclusively localized near the plasma membrane, and mitochondria containing Bax only were distributed throughout the cell. Different localization and protein 
content suggests the possibility of two functionally different populations similar to functionally different subpopulations of mitochondria in skeletal and cardiac muscle, or in pancreatic acinar cells (Park et al. 2001; Adhihetty et al. 2005; Williamson et al. 2009).

\section{Materials and Methods}

\section{Cell culture}

U-87 MG human glioma cells (Cell Lines Services, Germany) were plated and maintained according propagation protocols onto $35 \mathrm{~mm}$ culture dishes with integral No.0 glass cover slip bottoms (MatTek, USA). The U-87 MG cells were grown in Dulbecco's modified Eagle medium (D-MEM, Gibco-Invitrogen (Life Technologies LTD) with high glucose (4500 mg/l) supplemented with 10\% FBS (Fetal bovine serum) or serum substitute $2 \%$ Ultroser $\mathrm{G}$, in the presence of $5 \% \mathrm{CO}_{2}$ humidified atmosphere at $37^{\circ} \mathrm{C}$. Cells were incubated in dark. After reaching 40-50\% confluence, cells were treated according PDT protocol, followed by immunocytochemistry.

\section{PDT protocol}

U-87 MG human glioma cells were grown in D-MEM supplemented with $2 \%$ Ultroser $G$ for 24 hours. After that cells were incubated one hour with Hyp (Sigma-Aldrich; final concentration either 90 or $500 \mathrm{nM}$ ), in the presence of $5 \%$ $\mathrm{CO}_{2}$ humidified atmosphere at $37^{\circ} \mathrm{C}$. For all experiments final content of DMSO was less than $0.1 \%$. After the incubation with Hyp in Ultroser G (artificial serum substitute without lipids, BioSepra SA, France) containing media, cell media were changed to D-MEM containing 10\% FBS. Cells were then illuminated by light of $590 \mathrm{~nm}$ wavelength at the light dose of $4 \mathrm{~J} / \mathrm{cm}^{2}$. After the illumination, cells were placed in the $\mathrm{CO}_{2}$ incubator for one hour in dark. After one hour cells were fixed according immunocytochemistry protocol.

\section{Mitotracker protocol}

Prior immunocytochemistry U-87 MG cells were incubated in 2\% UG media with MitoTracker Orange CMTMRos (Invitrogen), final concentration $400 \mathrm{nM}$, for $5 \mathrm{~min}$ at room temperature. Cells were then fixed according the protocol below.

\section{Immunocytochemistry protocol}

Cell cultures were plated onto $35 \mathrm{~mm}$ culture dishes with integral No.0 glass cover slip bottoms (MatTek, USA). The cells were fixed with $100 \%$ methanol at $-20^{\circ} \mathrm{C}$ for a minimum of $20 \mathrm{~min}$. Cells were then incubated $1 \mathrm{~h}$ in PBS (Phosphate-Buffered Saline) containing 1\% BSA (bovine serum albumin), $10 \%$ goat serum, $0.4 \mathrm{mM} \mathrm{Mg}^{2+}$ and $0.2 \mathrm{mM} \mathrm{Ca}^{2+}$ to block unspecific labeling. After 3 washes with PBS/BSA $(0.2 \%)$, cells were incubated with specific primary antibody (Ab) against Bak (anti-Bak NT, $\psi$ ProSci Inc., USA) overnight at $4^{\circ} \mathrm{C}$. Cells were washed out 3 times with PBS/BSA (0.2\%), followed by $1 \mathrm{~h}$ incubation with appropriate secondary $\mathrm{Ab}$ conjugated with Alexa 488 (Life Technologies LTD) at $37^{\circ} \mathrm{C}$. Cells were then washed 3 times with PBS/BSA (0.2\%) to remove unbind secondary Ab. After 3 washes with PBS/BSA $(0.2 \%)$, cells were incubated with specific primary Ab against Bax (anti-Bax 2D2, Enzo Life Sciences AG Switzerland) for $1 \mathrm{~h}$ at $37^{\circ} \mathrm{C}$. Cells were washed out 3 times with PBS/BSA $(0.2 \%)$, followed by $1 \mathrm{~h}$ incubation with appropriate secondary Ab conjugated with Alexa 546 (Life Technologies LTD) at room temperature. Cells were then washed 3 times with PBS/BSA $(0.2 \%)$ to remove unbind secondary Ab and placed in $\mathrm{PBS} / \mathrm{BSA}(0.2 \%)$.

\section{Confocal microscopy}

Cells were placed in PBS/BSA (0.2\%), and assessed with a $63 \times$ oil objective $(\mathrm{NA}=1.46)$ of LSM 700 confocal microscope system (LSM 700, Zeiss Germany). The laser line $(488 \mathrm{~nm})$ of the argon laser was used to excite Alexa 488 fluorophore. Emissions of Alexa 488 were recorded in single-track configuration with a band-pass filter of 490 to $555 \mathrm{~nm}$. The laser line (555 nm) of the argon laser was used to excite Alexa 546 or Mitotracker Orange fluorophore. Emissions of Alexa 546 or Mitotracker Orange fluorophore were recorded in single-track configuration with a long-pass filter of $560 \mathrm{~nm}$. Fluorescence signals were analyzed by the Zen 2011 software (Zeiss, Germany). Cells were scanned in Z-stack mode with $0.75 \mu \mathrm{m}$ slice width. Cells' total widths varied between $7-12 \mu \mathrm{m}$.

\section{Co-localization analysis}

Co-localization analysis was performed on obtained fluorescence images using the Zen 2011 image processing software (Zeiss). Mander's coefficient (M; Eq. 1.), was used for colocalization analysis:

$$
\begin{gathered}
M=\frac{\sum_{i} G i \times R i}{\sqrt{\left(\sum_{i}(G i)^{2} \times \sum_{i}(R i)^{2}\right)}} \\
M_{\text {Green }}=\frac{\sum_{i} G_{i, \text { co-loc }}}{\sum_{i} G_{i, \text { total }}}
\end{gathered}
$$

$$
M_{\text {Red }}=\frac{\sum_{i} R_{i, c o-l o c}}{\sum_{i} R_{i, t o t a l}}
$$


$M$-values can vary within the range from 0 to $1.100 \% \mathrm{co}$ localization corresponds to $\mathrm{M}=1 . R_{i}$ and $G_{i}$ are the signal intensity of the pixel number " $i$ " obtained in the red and the green channel, respectively. Mander's coefficient does not depend on the relative strengths of each channel, but can be affected by the background signal (Bolte and Cordelieres 2006). To circumvent this limit, $M_{\text {Red }}$ and $M_{\text {Green }}$ were calculated by setting the threshold to the value of background.

\section{Statistical analysis}

Experiments under all conditions were done in at least three independent repetitions. Mean and standard errors (SEM) were evaluated in at least three independent experiments. Statistical analysis was carried out by Student's $t$-test using SigmaPlot (Ver. 9.0). A $p<0.05$ was considered as significance.

\section{Results}

\section{Mapping Bax and Bak distribution in U-87 MG glioma cells} under controlled conditions

To characterize the U-87 MG cell line, we used specific Abs recognizing Bax (anti-Bax 2D2) and Bak (anti-Bak NT). Cells were cultured and stained as described in the protocols and assessed by confocal microscope. Fig. 1 shows cells under controlled conditions double stained with Abs Bax 2D2 and Bak NT. In U-87 MG cells under control conditions, Bak, visualized by Alexa 488 secondary Ab (green signal), localized predominantly in small foci, which are presumably mitochondria. Foci were distributed homogenously throughout the cell as it can be seen from distribution patterns in different cell depth at $\approx 1 \mu \mathrm{m}$ (Fig. 1A) and $3 \mu \mathrm{m}$ (Fig. 1B), respectively. Bax, visualized by Alexa 546 secondary $\mathrm{Ab}$ (red signal), localized in cytosol and in small portion was peripherally attached to foci/mitochondria. Mitochondria containing Bax were also evenly distributed throughout the cell. Under controlled conditions, there were mitochondria containing Bak only, Bax only, and mitochondria containing simultaneously both proteins Bax and Bak. The latter were aligned mostly along plasma membrane and there was partial co-localization of Bax with Bak as it is indicated by Mander's coefficient $(\mathrm{M}=0.71$; Table 1$)$. The mitochondria localized deeper inside the cells and containing simultaneously both proteins Bax and Bak were few, and co-localization of Bax with Bak was significantly less $(p<0.05)$ than in those along plasma membrane.

To determine whether small foci are mitochondria, we used the mitochondria specific marker Mitotracker Orange ${ }^{\otimes}$ CMTMRos known to be retained in cells after fixation (MitoTracker ${ }^{\oplus}$ Mitochondrion-Selective Probes manual). Fig. 2 shows mitochondria stained with Mitotracker Orange ${ }^{\bullet}$ CMTMRos (200 nM; 5 min incubation) in the U-87 MG live cells under control conditions prior (Fig. 2A) and after fixation by $\mathrm{MetOH}$ (Fig. 2B). It is clear that signal in live cells was much stronger, but there was sufficient signal retained in the fixed cells as well.

Fig. 3 shows cells stained with Mitotracker Orange ${ }^{\circledR}$ CMTMRos (400 nM; 5 min incubation) prior fixation. Cells were then fixed and stained according immunocytochemistry protocol with primary Ab either BakNT or Bax 2D2 followed by appropriate secondary Ab Alexa 488 (green fluorescent signal). In panel A of Fig. 3, it seems that most of the green foci corresponding to Bak are localized at or near mitochondria (red signal corresponds to Mitotracker Orange, Fig. 3A). In panel B, green fluorescent signal corresponds to Bax and has more diffuse character, corresponding to Bax cytoplasmic localization. However, stronger signal in green foci co-localizes with Mitotracker signal, suggesting some Bax is peripherally attached to mitochondria.

To determine how presence of Hyp itself, and photodynamic action affect mitochondria pattern, we use the cells under different conditions (control cell - no Hyp no PDT; 500 nM Hyp without irradiation, and 500 nM Hyp plus PDT) stained with Mitotracker Orange ${ }^{\circledR}$ CMTMRos (400 nM; 5 min incubation) prior fixation. Cells were then fixed according

Table 1. Co-localization analysis of Bax with Bak

\begin{tabular}{|c|c|c|c|c|c|c|c|}
\hline & \multicolumn{2}{|c|}{$\begin{array}{l}\text { Mitochondria near cell } \\
\text { membrane at } 1 \mu \mathrm{m} \text { depth }\end{array}$} & \multicolumn{2}{|c|}{$\begin{array}{l}\text { Mitochondria near cell } \\
\text { membrane at } 3 \mu \mathrm{m} \text { depth }\end{array}$} & \multicolumn{2}{|c|}{$\begin{array}{l}\text { Mitochondria in the cell interior } \\
\text { at } 3 \mu \mathrm{m} \text { depth }\end{array}$} & \multirow[t]{2}{*}{$n$} \\
\hline & Mander's $c$ & $M_{\text {red }}$ & Mander's c. & $M_{\text {red }}$ & Mander's $c$. & $M_{\text {red }}$ & \\
\hline Control & $0.71 \pm 0.02$ & $0.67 \pm 0.05$ & $0.68 \pm 0.03$ & $0.64 \pm 0.06$ & $0.56 \pm 0.04$ & $0.34 \pm 0.05$ & 17 \\
\hline 500 Hyp dark & $0.58^{*} \pm 0.03$ & $0.48 \pm 0.05$ & $0.52^{\star} \pm 0.03$ & $0.46 \pm 0.05$ & $0.40^{\#} \pm 0.06$ & $0.13 \pm 0.03$ & 22 \\
\hline 500 HypPDT & $0.86^{\ddagger} \pm 0.02$ & $0.81 \pm 0.04$ & $0.82^{\ddagger} \pm 0.02$ & $0.75 \pm 0.05$ & $0.07^{\ddagger} \pm 0.03$ & $0.16 \pm 0.05$ & 18 \\
\hline
\end{tabular}

Mander's c. is Mander's coefficient (see Eq. 1, Materials and Methods) of co-localization (min. value of 0 means no co-localization, max. value of 1 indicate $100 \%$ co-localization). The $M_{\text {red }}$ is weighted co-localization coefficient (see Eq. 3, Materials and Methods) it displays how well the red pixels (Bax fluorescence) above threshold co-localize with the overall sum of pixels above threshold. This gives information about the relative presence of Bax fluorescence in a vicinity of Bak. ${ }^{\star} p<0.001,{ }^{\ddagger} p<0.0001 ;{ }^{*} p<0.03$. 
A

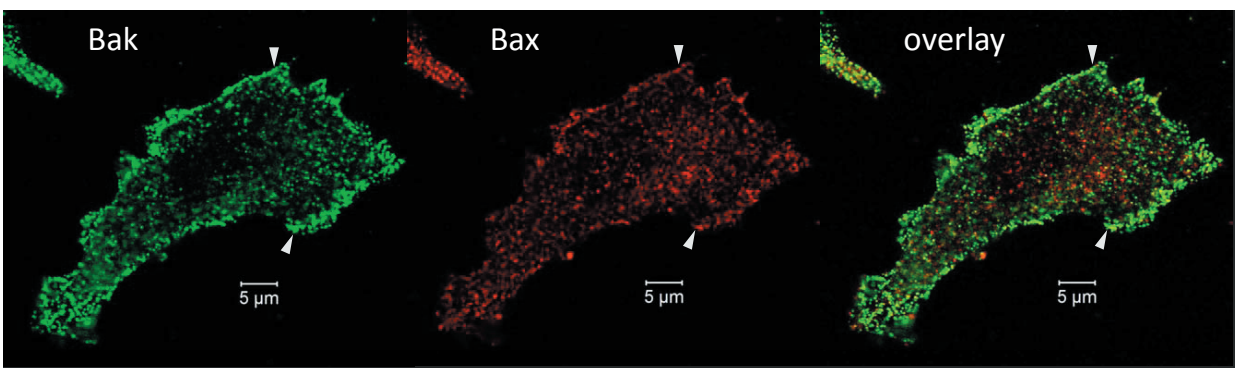

B

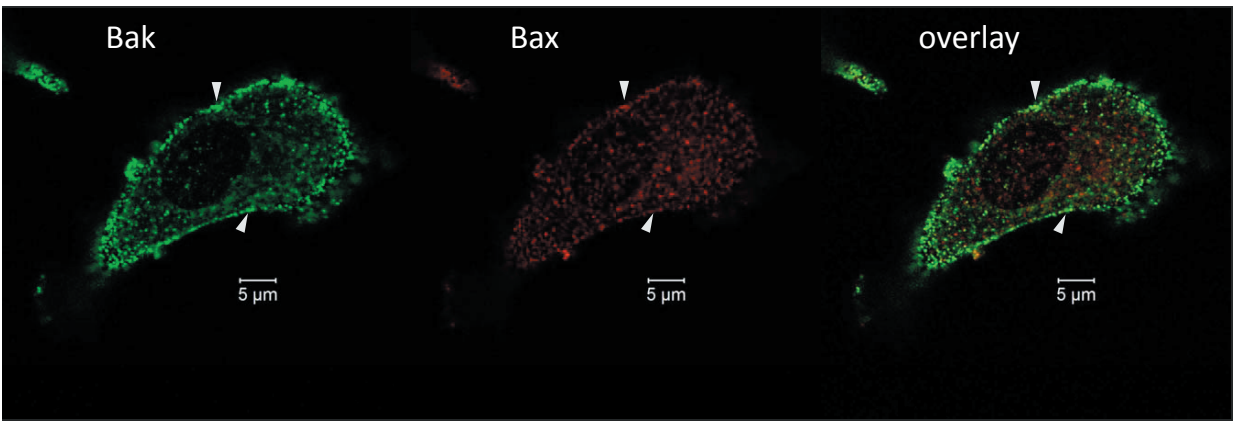

Figure 1. Bax and Bak distribution in U-87 MG glioma cells under controlled conditions.Figure shows immunofluorescence microscopy of Bak (green fluorescence) and Bax (red fluorescence) in the depth of $1 \mu \mathrm{m}(\mathbf{A})$ and $3 \mu \mathrm{m}$ (B) from cell plasma membrane. Green fluorescence appears as small green foci evenly distributed in cell. Red fluorescence has diffuse character and in small portion appears in red foci localized along plasma membrane. Right panels in A and B represent overlay of green and red fluorescence. White arrows indicate co-localization of green and red foci. The scale bar corresponds to $5 \mu \mathrm{m}$. immunocytochemistry protocol without any additional staining. Fig. 4A shows cell under control condition without Hyp present. Mitochondria show a typical networking pattern. Presence of 500 nM Hyp itself without irradiation does not affect mitochondria pattern (Fig. 4B). However, immediately after HypPDT, we observed change in pattern (Fig. 4C). Mitochondria were no longer in network, they seem to disperse to more discrete foci. We cannot observe mitochondria pattern in cells by Mitotracker Orange ${ }^{\circ} \mathrm{CMTMR}$ os in the longer period then immediately after HypPDT this stain is very sensitive to oxidation-reduction reactions resulting from PDT, and is no longer visible in fixed cells.

Bax and Bak distribution in U-87 MG glioma cells does not change in the presence of Hyp without irradiation

It has been shown that presence of free $500 \mathrm{nM}$ Hyp without irradiation does not affect viability U-87 MG glioma cells (Huntosova et al. 2012). In U-87 MG cells incubated with 500 nM Hypericin without irradiation, we did not observed differences in Bak and Bax distribution in comparison with cells under controlled conditions (data not shown). Bak was localized predominantly in mitochondria which were distributed homogenously throughout the cell. Bax was again localized in cytosol, and in small portion was peripherally attached to mitochondria. Mitochondria containing Bax or Bak were evenly distributed throughout the cell. At the presence of $500 \mathrm{nM}$ Hyp without irradiation, mitochondria containing simultaneously both proteins Bax and Bak were aligned mostly along plasma membrane. However, in the presence of Hyp co-localization of Bax with Bak decreased

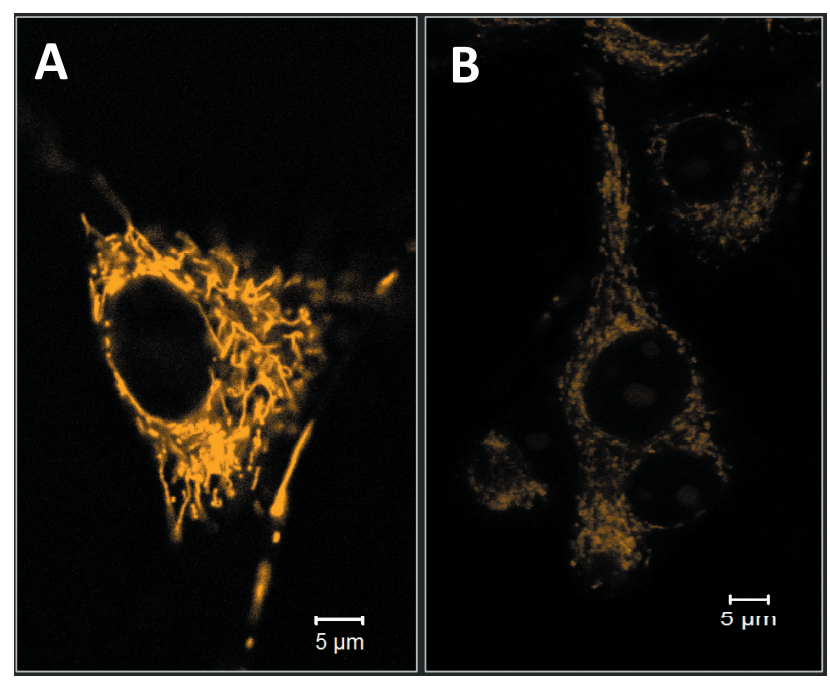

Figure 2. Fixed U-87 MG glioma cells retain sufficient Mitotracker Orange ${ }^{\circ} \mathrm{CMTMRos}$ signal. Figure shows fluorescent microscopy of Mitotracker Orange ${ }^{\circ} \mathrm{CMTMRos}$ (orange fluorescence) from live (A) and fixed (B) U-87 MG cells. Orange fluorescence shows stained mitochondria. The U-87 MG live cells were incubated 5 min with Mitotracker Orange ${ }^{\circ} \mathrm{CMTMRos}(200 \mathrm{nM})$ under control conditions and then assessed with confocal microscope prior (A) and after fixation by $\mathrm{MetOH}(\mathbf{B})$. Note that signal in live cells was much stronger, but there was sufficient signal retained in the fixed cells as well.

significantly $(p<0.001)$ in the mitochondria along plasma membrane (from $\mathrm{M}=0.71$ to $\mathrm{M}=0.58$, see Table 1 ) as well as in the mitochondria localized deeper $(p<0.03)$ inside the cells (from $M=0.56$ to $M=0.40$, see Table 1 ). 
A

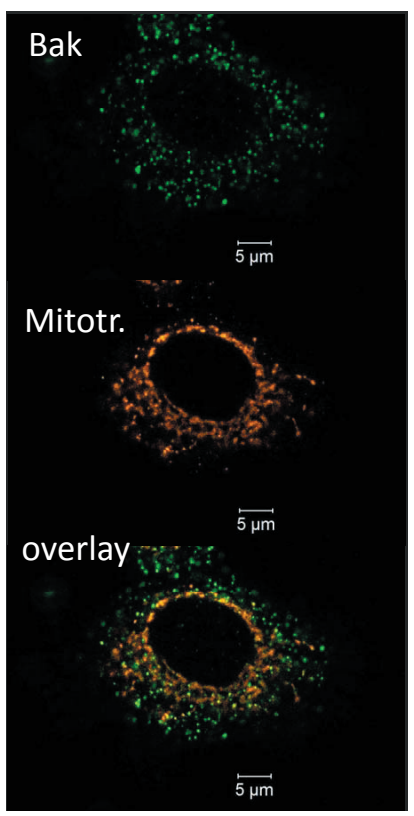

B

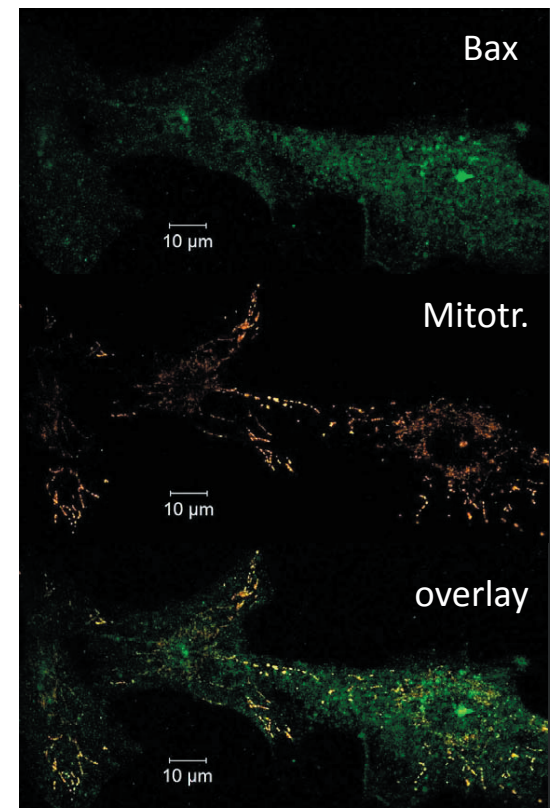

Figure 3. Co-localization of Bax and Bak with mitochondria in U-87 MG glioma cells under controlled conditions. A. Immunofluorescence microscopy of Bak (green fluorescence, left panel) and Mitotracker Orange ${ }^{\circ} \mathrm{CMTMRos}$ (red fluorescence, right panel). Lower panel shows overlay of green and red fluorescence. Note that majority of green foci overlap with red fluorescence. B. Immunofluorescence microscopy of Bax (green fluorescence, upper panel) and Mitotracker Orange ${ }^{\circ}$ CMTMRos (red fluorescence, middle panel). Bottom panel shows overlay of green and red fluorescence. Note that majority of green fluorescence does not overlap with red, which corresponds to Bax cytoplasmic localization. Only few green foci seem to overlap with red fluorescence, corresponding to Bax peripherally attached to mitochondria.

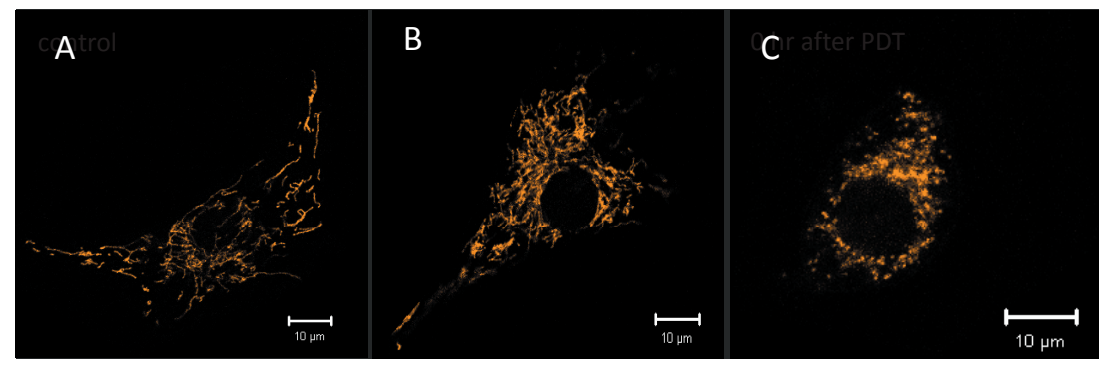

Figure 4. Effect of Hyp photodynamic action on the mitochondria distribution pattern in U-87 MG glioma cells. Figure shows fluorescent images of Mitotracker Orange - CMTMRos (orange fluorescence) in fixed U-87 MG cells. Orange fluorescence shows stained mitochondria. The U-87 MG live cells were incubated 5 min with Mitotracker Orange ${ }^{\circ} \mathrm{CMTMRos}(400 \mathrm{nM})$ prior fixation. A. Mitochondria networking pattern in the U-87 MG cells under controlled condition in the absence of Hyp. B. Mitochondria pattern in the presence of 500 nM Hyp without irradiation. Pattern is similar to the one in A. C. Mitochondria pattern in the presence of $500 \mathrm{nM}$ Hyp immediately after photodynamic action. Please note, that mitochondria are localized in more discrete foci, and networking pattern is much less noticeable.

A

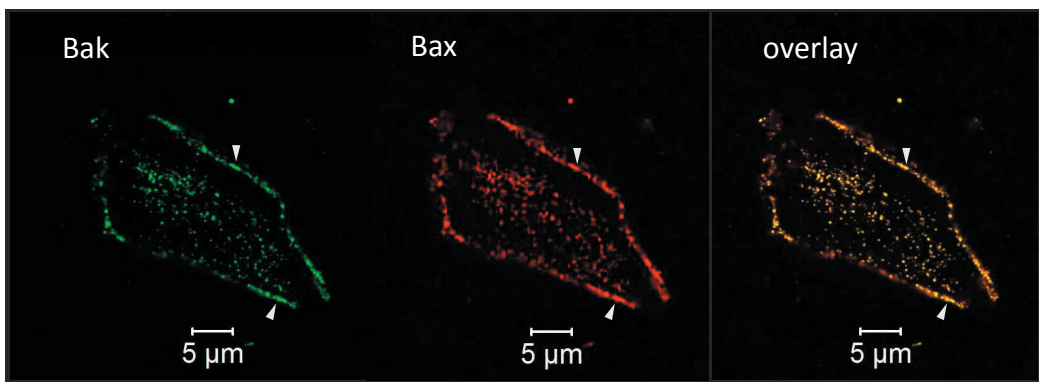

B

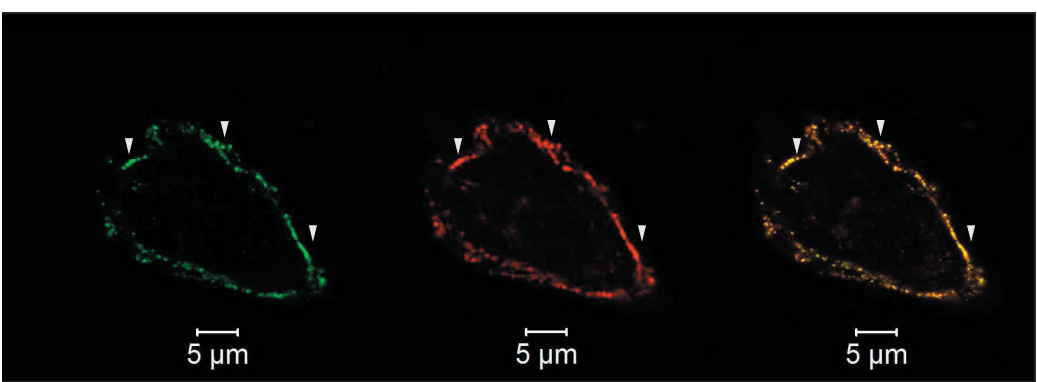

Figure 5. HypPDT activates and translocates Bax into mitochondria. Figure shows distribution and co-localization of Bax and Bak in U-87 MG glioma cells one hour after HypPDT. It shows immunofluorescence microscopy of Bak (green fluorescence) and Bax (red fluorescence) in the depth of $1 \mu \mathrm{m}$ (A) and $3 \mu \mathrm{m}$ (B) from cell plasma membrane. Green fluorescence appears as small green foci localized mostly along plasma membrane. Red fluorescence appears also in red foci localized along plasma membrane. Bottom panels in A and B represent overlay of green and red fluorescence. White arrows indicate co-localization of green and red foci. Please note that overlap of green and red fluorescence is near $90 \%$. The scale bar corresponds to $5 \mu \mathrm{m}$. 
Bax and Bak distribution in U-87 MG glioma cells one hour after Hyp irradiation

One hour after incubation with 500 nM Hyp U-87 MG cells were illuminated by light of $590 \mathrm{~nm}$ wavelength according the PDT protocol (see Materials and Methods). After the illumination, cells were placed in the $\mathrm{CO}_{2}$ incubator for one hour in dark. After one hour cells were fixed according immunocytochemistry protocol and assessed by confocal microscopy. Hyp irradiation according PDT protocol used here results in apoptosis in U-87 MG cells in time-dependent manner (Huntosova et al. 2012).

One hour after an apoptotic stimulus (HypPDT), we observed significant changes in Bax and Bak distribution in U-87 MG glioma cells (Fig. 4). Bak containing mitochondria move predominantly towards plasma membrane as it can be seen by the difference in green fluorescent signal at cell depth of $\approx 1$ and $3 \mu \mathrm{m}$, respectively (Fig. 5A and 5B). There is increase in bright red foci in cells after PDT treatment (Fig. 5, middle panel Bax) in comparison with cells under controlled conditions (Fig. 1, middle panel Bax), suggesting activation and translocation of Bax into mitochondria. One hour after HypPDT, almost all of the mitochondria containing simultaneously both proteins Bax and Bak were aligned within $1 \mu \mathrm{m}$ of plasma membrane throughout the all z-stack slices. Co-localization of Bax with Bak in those increased significantly $(p<0.0001)$ from $M=0.58$ to 0.86 (Table 1 ) in comparison with cells incubated with Hyp without irradiation. The mitochondria localized deeper inside the cells, and containing Bax and Bak, practically diminished as it can be seen in Fig. 5B. In some cells, we could still see some mitochondria deeper inside, which contained Bax only.

\section{Discussion}

The aim of this study was to map distribution of pro-apoptotic proteins Bax and Bak before and after HypPDT in U-87 MG glioma cells. Our study indicates that there are two distinct populations of mitochondria in U-87 MG glioma cells: one which can contains Bax and Bak simultaneously, and another which contains Bax only. Under controlled conditions, both populations were distributed evenly throughout the cell. Distributions of two distinct populations of mitochondria were significantly different after HypPDT. Mitochondria containing Bax and Bak simultaneously are almost exclusively localized near plasma membrane (Fig. 5), and mitochondria containing Bax only are sparsely distributed throughout the cell. The different protein content and spatial distribution of these two populations suggest that they can play different roles in response to apoptotic stimuli.

Under controlled conditions in U-87 MG glioma cells, Bak was localized predominantly in mitochondria which were dis- tributed homogenously throughout the cell. Bax was localized in cytosol and in small portion was peripherally attached to mitochondria. We verified that fluorescent foci for the most part are co-localizing with mitochondria and distribution pattern is similar to those observed by fused fluorescent proteins GFP-Bak and GFP-Bax (Nechushtan et al. 1999, 2001).

In agreement with known Hyp characteristics (Agostinis et al. 2002; Miskovsky 2002), we did not observed any toxicity caused by Hyp without irradiation. However, we did observe significant $(p<0.001)$ decrease in the presence of Bax in Bak containing mitochondria. This may be a result of direct interaction of Hyp and Bax. It has been shown that Hyp can affect other protein (PKC $\alpha$ - protein kinase $\mathrm{C} \alpha$ ) distribution pattern due to hydrophobic protein-protein interaction (Kocanova et al. 2006).

One hour after HypPDT, we observed a significant increase in Bax translocation into mitochondria, suggesting a triggered apoptotic pathway. This seems to be a more sensitive method for the detection of apoptosis onset than flow-cytometric analysis. Flow-cytometric analysis of U-87 glioma cells stained with propidium iodide and AnnexinV-FITC one hour after $500 \mathrm{nM}$ free Hyp irradiation did not revealed any significant difference in apoptosis in comparison with control cells (Huntosova et al. 2012). In addition, the observed patterns of two spatially distinct mitochondria population after HypPDT, which also differ in protein makeup, suggest that these may have also different function in cell response. The finding of two distinct mitochondria populations was not yet reported for glioma cells, however, similar findings were reported for spatially and functionally different subpopulations of mitochondria in skeletal and cardiac muscle, and in pancreatic acinar cells (Park et al. 2001; Adhihetty et al. 2005; Williamson et al. 2009).

\section{Conclusions}

Our study shows distribution patterns of pro-apoptotic proteins Bax and Bak before and after HypPDT in U-87 MG glioma cells. The study indicates that there are two distinct populations of mitochondria in U-87 MG glioma cells. Different protein content and spatial distribution of these two populations suggest that they may play different roles in response to apoptotic stimuli.

Acknowledgements: Supported by the grants of PIRG06-GA-2009256580 (Marie Curie Actions FP7-PEOPLE-2009-RG, EU), Center for excellent research of atherosclerosis (034/2009/2.1/OPR\&D).

\section{References}

Adhihetty P. J., Ljubicic V., Menzies K. J., Hood D. A. (2005): Differential susceptibility of subsarcolemmal and intermyofibrillar 
mitochondria to apoptotic stimuli. Am. J. Physiol. Cell Physiol. 289, C994-1001

http://dx.doi.org/10.1152/ajpcell.00031.2005

Agostinis P., Vantieghem A., Merlevede W., de Witte P. A. M. (2002): Hypericin in cancer treatment: more light on the way. Int. J. Biochem. Cell B. 34, 221-241

http://dx.doi.org/10.1016/S1357-2725(01)00126-1

Ali S. M., Olivo M. (2002): Bio-distribution and subcellular localization of Hypericin and its role in PDT induced apoptosis in cancer cells. Int. J. Oncol. 21, 531-540

Annis M. G., Yethon J. A., Leber B., Andrews D. W. (2004): There is more to life and death than mitochondria: $\mathrm{Bcl}-2$ proteins at the endoplasmic reticulum. Biochim. Biophys. Acta 1644, 115-123 http://dx.doi.org/10.1016/j.bbamcr.2003.07.001

Bhuvaneswari R., Gan Y. Y., Yee K. K., Soo K. C., Olivo M. (2007): Effect of hypericin-mediated photodynamic therapy on the expression of vascular endothelial growth factor in human nasopharyngeal carcinoma. Int. J. Mol. Med. 20, 421-428

Bolte S., Cordelieres F.P. (2006): A guided tour into subcellular colocalization analysis in light microscopy. J. Microsc. 224, 213-232 http://dx.doi.org/10.1111/j.1365-2818.2006.01706.x

Buytaert E., Callewaert G., Hendrickx N., Scorrano L., Hartmann D., Missiaen L., Vandenheede J. R., Heirman I., Grooten J., Agostinis P. (2006): Role of endoplasmic reticulum depletion and multidomain proapoptotic BAX and BAK proteins in shaping cell death after hypericin-mediated photodynamic therapy. FASEB J. 20, 756-758

Cerrato J. A., Yung W. K., Liu T.-J. (2001): Introduction of mutant p53 into a wild-type p53-expressing glioma cell line confers sensitivity to Ad-p53-induced apoptosis. Neuro. Oncol. 3, 113-122

Chavakis E., Dimmeler S. (2002): Regulation of endothelial cell survival and apoptosis during angiogenesis. Arterioscler. Thromb. Vasc. Biol. 22, 887-893 http://dx.doi.org/10.1161/01.ATV.0000017728.55907.A9

English D. S., Doyle R. T., Petrich J. W., Haydon P. G. (1999): Subcellular distributions and excited-state processes of hypericin in neurons. Photochem. Photobiol. 69, 301-305 http://dx.doi.org/10.1562/0031-8655(1999)069<0301:SDAE$\mathrm{SP}>2.3 . \mathrm{CO} ; 2$

Galanou M.C., Theodossiou T. A., Tsiourvas D., Sideratou Z., Paleos C. M. (2008): Interactive transport, subcellular relocation and enhanced phototoxicity of hypericin encapsulated in guanidinylated liposomes via molecular recognition. Photochem. Photobiol. 84, 1073-1083

Gilmore A. P., Metcalfe A. D., Romer L. H., Streuli C. H. (2000): Integrin-mediated survival signals regulate the apoptotic function of Bax through its conformation and subcellular localization. J. Cell Biol. 149, 431-446 http://dx.doi.org/10.1083/jcb.149.2.431

Goping I. S., Gross A., Lavoie J. N., Nguyen M., Jemmerson R., Roth K., Korsmeyer S. J., Shore G.C. (1998): Regulated targeting of BAX to mitochondria. J. Cell Biol. 143, 207-215 http://dx.doi.org/10.1083/jcb.143.1.207

Hakem R., Hakem A., Duncan G. S., Henderson J. T., Woo M., Soengas M. S., Elia A., de la Pompa J. L., Kagi D., Khoo W., Potter J., Yoshida R., Kaufman S. A., Lowe S. W., Penninger J.
M., Mak T. W. (1998): Differential requirement for caspase 9 in apoptotic pathways in vivo. Cell 94, 339-352 http://dx.doi.org/10.1016/S0092-8674(00)81477-4

Hsiao P. N., Chang M. C., Cheng W. F., Chen C. A., Lin H. W., Hsieh C. Y., Sun W. Z. (2009): Morphine induces apoptosis of human endothelial cells through nitric oxide and reactive oxygen species pathways. Toxicology 256, 83-91

http://dx.doi.org/10.1016/j.tox.2008.11.015

Huntosova V., Nadova Z., Dzurova L., Jakusova V., Sureau F., Miskovsky P. (2012): Cell death response of U87 glioma cells on hypericin photoactivation is mediated by dynamics of hypericin subcellular distribution and its aggregation in cellular organelles. Photochem. Photobiol. Sci. 11, 1428-1436 http://dx.doi.org/10.1039/c2pp05409d

Hwang S.-I., Lundgren D. H., Mayya V., Rezaul K., Cowan A. E., Eng J. K., Han D. K. (2006): Systematic characterization of nuclear proteome during apoptosis. Mol. Cell Proteomics 5, $1131-1145$ http://dx.doi.org/10.1074/mcp.M500162-MCP200

Kascakova S., Nadova Z., Mateasik A., Mikes J., Huntosova V., Refregiers M., Sureau F., Maurizot J.-C., Miskovsky P., Jancura D. (2008): High Level of Low-density Lipoprotein Receptors Enhance Hypericin Uptake by U-87 MG Cells in the Presence of LDL. Photochem. Photobiol. 84, 120-127

Kiesslich T., Krammer B., Plaetzer K. (2006): Cellular mechanisms and prospective applications of hypericin in photodynamic therapy. Curr. Med. Chem. 13, 2189-2204 http://dx.doi.org/10.2174/092986706777935267

Kleban J., Mikeš J., Horváth V., Sačková V., Hofmanová J., Kozubík A., Fedoročko P. (2008): Mechanisms involved in the cell cycle and apoptosis of HT-29 cells pre-treated with MK-886 prior to photodynamic therapy with hypericin. J. Photochem. Photobiol. B. 93, 108-118 http://dx.doi.org/10.1016/j.jphotobiol.2008.07.007

Kocanova S., Hornakova T., Hritz J., Jancura D., Chorvat D. Jr., Mateasik A., Ulicny J., Refregiers M., Maurizot J.-C., Miskovsky P. (2006): Characterization of the interaction of Hypericin with Protein Kinase C in U-87 MG human glioma cells. Photochem. Photobiol. 82, 720-728 http://dx.doi.org/10.1562/2005-09-26-RA-696

Kroemer G. (1997): The proto-oncogene Bcl-2 and its role in regulating apoptosis. Nat. Med. 3, 614-620 http://dx.doi.org/10.1038/nm0697-614

Lindsay J., Esposti M. D., Gilmore A. P. (2011): Bcl-2 proteins and mitochondria - Specificity in membrane targeting for death. Biochim. Biophys. Acta 1813, 532-539 http://dx.doi.org/10.1016/j.bbamcr.2010.10.017

Miskovsky P. (2002): Hypericin - A new antiviral and antitumor photosensitizer: mechanism of action and interaction with biological macromolecules. Curr. Drug Targets 3, 55-84 http://dx.doi.org/10.2174/1389450023348091

Nechushtan A., Smith C. L., Hsu Y. T., Youle R. J. (1999): Conformation of the Bax C-terminus regulates subcellular location and cell death. EMBO J. 18, 2330-2341 http://dx.doi.org/10.1093/emboj/18.9.2330

Nechushtan A., Smith C. L., Lamensdorf I., Yoon S. H., Youle R. J. (2001): Bax and Bak coalesce into novel mitochondria-associated clusters during apoptosis. J. Cell Biol. 153, 1265-1276 
http://dx.doi.org/10.1083/jcb.153.6.1265

Park M. K., Ashby M. C., Erdemli G., Petersen O. H., Tepikin A. V. (2001): Perinuclear, perigranular and sub-plasmalemmal mitochondria have distinct functions in the regulation of cellular calcium transport. EMBO J. 20, 1863-1874 http://dx.doi.org/10.1093/emboj/20.8.1863

Reeves K. J., Reed M. W., Brown N. J. (2009): Is nitric oxide important in photodynamic therapy? J. Photochem. Photobiol. B. 95, 141-147 http://dx.doi.org/10.1016/j.jphotobiol.2009.02.005

Renno R. Z., Delori F. C., Holzer R. A., Gragoudas E. S., Miller J. W. (2000): Photodynamic therapy using lu-tex induces apoptosis in vitro, and its effect is potentiated by angiostatin in retinal capillary endothelial cells. Invest. Ophth. Vis. Sci. 41, 3963-3971

Rieger, Bornemann A., Schabet M., Dichgans J., Meyermann R. (1998): BCL-2 family protein expression in human malignant glioma: a clinical-pathological correlative study. J. Neurol. Sci. $155,68-75$ http://dx.doi.org/10.1016/S0022-510X(97)00277-3

Scorrano L., Oakes S. A., Opferman J. T., Cheng E. H., Sorcinelli M. D., Pozzan T., Korsmeyer S. J. (2003): BAX and BAK regulation of endoplasmic reticulum $\mathrm{Ca} 2+$ : a control point for apoptosis. Science 300, 135-139 http://dx.doi.org/10.1126/science.1081208

Siboni G., Weitman H., Freeman D., Mazur Y., Malik Z., Ehrenberg B. (2002): The correlation between hydrophilicity of hypericins and helianthrone: Internalization mechanisms, subcellular distribution and photodynamic action in colon carcinoma cells. Photochem. Photobiol. Sci. 1, 483-491 http://dx.doi.org/10.1039/b202884k

Steinberg R., Harari O. A., Lidington E. A., Boyle J. J., Nohadani M., Samarel A. M., Ohba M., Haskard D. O., Mason J. C. (2007): A protein kinase Cepsilon-anti-apoptotic kinase signaling complex protects human vascular endothelial cells against apoptosis through induction of Bcl-2. J. Biol. Chem. 282, 32288-32297 http://dx.doi.org/10.1074/jbc.M704001200

Theodossiou T. A, Noronha-Dutra A., Hothersall J. S. (2006): Mitochondria are a primary target of hypericin phototoxicity: Synergy of intracellular calcium mobilisation in cell killing. Int. J. Biochem. Cell B. 38, 1946-1956 http://dx.doi.org/10.1016/j.biocel.2006.05.009

Valentijn A. J., Metcalfe A. D., Kott J., Streuli C. H., Gilmore A.P. (2003): Spatial and temporal changes in Bax subcellular localization during anoikis. J. Cell Biol. 162, 599-612 http://dx.doi.org/10.1083/jcb.200302154

Youle R. J., Strasser A. (2008): The BCL-2 protein family: opposing activities that mediate cell death. Nat. Rev. Mol. Cell Biol. 9, 47-59 http://dx.doi.org/10.1038/nrm2308

Wang F., Bhat K., Doucette M., Zhou S., Gu Y., Law B., Liu X., Wong E. T., Kang J. X., Hsieh T.-C., Qian S. Y., Wu E. (2011): Docosahexaenoic acid (DHA) sensitizes brain tumor cells to etoposide-induced apoptosis. Curr. Mol. Med. 11, 503-511 http://dx.doi.org/10.2174/156652411796268740

Williamson C. L., Dabkowski E. R., Baseler W. A., Croston T. L., Alway S. E., Hollander J. M. (2010): Enhanced apoptotic propensity in diabetic cardiac mitochondria: influence of subcellular spatial location. Am. J. Physiol. Heart Circ. Physiol. 298, H633-642

http://dx.doi.org/10.1152/ajpheart.00668.200

Received: June 29, 2012

Final version accepted: October 9, 2012 